\title{
SPATIO-TEMPORAL MOBILITY OF APICULTURE AFFECTED BY THE CLIMATE CHANGE IN THE BEEKEEPING OF THE GULF OF MEXICO
}

\author{
CASTELLANOS-POTENCIANO, B. ${ }^{1}$ - GALLARDO-LÓPEZ, F. ${ }^{1 *}$ - DÍAZ-PADILLA, G. $^{2}$ \\ PÉREZ-VÁZQUEZ, A. ${ }^{1}$ - LANDEROS-SÁNCHEZ, C. ${ }^{1}$ \\ ${ }^{1}$ Colegio de Postgraduados, Campus Veracruz. Manlio Fabio Altamirano, México \\ e-mail: bcastellanos@colpos.mx,felipegl@colpos.mx,parturo@colpos.mx, \\ clandero@colpos.mx \\ ${ }^{2}$ Instituto Nacional de Investigaciones Forestales, Agricolas y Pecuarias, C.E. Cotaxtla, \\ Medellín de Bravo, México \\ e-mail:diaz.gabriel@inifap.gob.mx \\ *Corresponding author \\ e-mail:felipegl@colpos.mx
}

(Received $7^{\text {th }}$ Feb 2017; accepted $10^{\text {th }}$ May 2017)

\begin{abstract}
One the effects of climate change on populations has been the alteration in the geographical limits and spatial mobility of plants, which generates changes with associated species, such as honeybees which could produce changes in beekeeping. The aim of this study was to determine the spatio-temporal mobility of beekeeping, in the short, medium and long term, in the main honey-producing area in the Gulf of Mexico`s beekeeping region due to changes in temperature resulting from climate change using a regional assembly model with scenario A2. The productive potential of eight indicator melliferous species was determined: $C$. sinensis, $C$. paradisi, B. simaruba, $C$. arabica, A. germinans, $R$. mangle, B. nigra and $S$. mombin. The development potential for A. mellifera was determined based on combining bee thermal comfort and melliferous species' information, forming four categories for apicultural development. Based on the type of flowering, beekeeping will be confronted by a loss of suitable area for citrus species and an increase in area for the rest of the indicator species, which demonstrated different changes according to each species from the short to the long term. Therefore, beekeeping will have a varied spatio-temporal mobility according to the availability of botanical resources and the thermal comfort of the honeybee.
\end{abstract}

Keywords: apiarian mobility, melliferous flora, beekeeping and climate change, Apis mellifera, honey

\section{Introduction}

Global temperature increases forecasted by the Intergovernmental Panel on Climate Change are estimated to range from 1.4 to $3.1^{\circ} \mathrm{C}$ over the next 100 years (IPCC, 2014). This will affect individuals, populations and species, as well as ecosystems, resulting in changes in the geographical limits and spatial and elevational mobility of plant communities. This will generate changes in space and time in ecosystem relationships with associated species (Bravo et al., 2011, Zhou et al., 2016).

Among the ecological relationships, the one which exists between plants and bees is one of the most valued since $35 \%$ of global food production comes from crops pollinated by bees (Saturni, 2016), and also because beekeeping is an economic activity seen as a tool for the development of the primary sector in different countries (Huerta, 2008).

In beekeeping, the honey yields that determine the sector's profitability are related to the weather conditions that directly and indirectly affect honeybee (Apis mellifera L.) dynamics (Delgado et al., 2012, Mendizabal, 2005) and plant phenology (Hegland et al., 
2009). Therefore, phenological processes related to thermo-pluvial variations are one of the main factors influencing ecosystems (Hildrew et al., 2017), as a result of climate change (Gomez-Diaz et al., 2007). Such variations affect bloom times due to increases in temperature, generating imbalances with pollinators associated with the vegetation (Tam and McDaniels, 2013).

Variation in vegetation phenology is an indicator in climate change ecosystems (Zhou et al., 2016). At regional scales, this impact has been underestimated for honey production (Delgado et al., 2012), which depends on the comfort state provided by the balance between the physiology of an organism and the environment that surrounds it, for optimum food transformation (Ruiz et al., 2011).

Therefore, the presence of tropical storms, hurricanes with destructive force and droughts as a result of climate change have an impact on bee production (Guemes et al., 2003), as well as its profitability (Magaña et al., 2016). In Mexico, honey production has maintained a downward trend (SIAP, 2015), which is attributed to, among other factors, the presence of erratic storms, early frosts and droughts that are not conducive to optimum flowering development (Contreras-Escareño et al., 2013). In 2005 and 2007 , a $11.1 \%$ reduction in honey production coincided with the presence of Hurricanes Wilma and Dean on the Yucatan Peninsula. However, in 2009 and 2010 a combination of the ENSO neutral and negative (La Niña) phases contributed to a $6.1 \%$ drop in domestic honey production (CONAGUA, 2011, SIAP, 2015).

Therefore, an alteration in the climatic system can define a new spatial distribution of bees intervening in the foraging relationships between species and races, as well as in the development of associated parasites and pathogens. This will force beekeepers to change their production methods in the coming decades (Le Conte and Navajas, 2008).

In countries such as Puerto Rico, the trend in terms of areas for honey production has been evaluated with climate projection models, based on future climate change scenarios. This is where a risk is foreseen in the form of a predicted reduction in the spatial areas suitable for apicultural development (Delgado et al., 2012).

The study of changes in beekeeping through future scenarios that allow projecting possible changes induced by climate change, based on the plant-insect relationship in tropical regions, would enable exploring the availability of suitable areas for apiculture in space and time, for the development of use and adaptation strategies.

In this regard, the aim of this research was to determine the spatio-temporal mobility of beekeeping in the central region of the state of Veracruz along the Gulf Coast in the short (2021-2030), medium (2041-2050) and long term (2051-2060), due to changes in temperature and precipitation resulting from climate change predicted by the SICC regional assembly projection model under scenario A2 conditions (IPCC, 2007). The information thus generated is intended to provide a comprehensive overview of the impacts that this phenomenon will have on beekeeping in this important apiarian region, considering the spatial area available for the development of melliferous species.

\section{Materials and Methods}

The study area was the main production area in the beekeeping region of the Gulf of

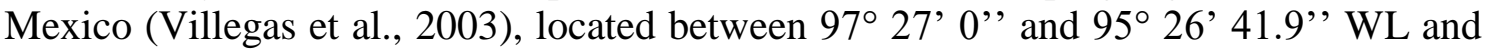
$18^{\circ} 31^{\prime}$ 'WL. This region comprises 20 municipalities in the state of Veracruz, namely: Altotonga, Alvarado, Atzalan, Boca del Rio, Coatepec, Comapa, Córdoba, Cosautlán de 
Carvajal, Emiliano Zapata, Ixhuacán de los Reyes. Jalacingo, Martínez de la Torre, San Rafael, Soledad de doblado, Teocelo, Tlapacoyan, Veracruz, Xalapa, Xico and Zentla.

The indicator melliferous species that account for the bulk of honey production and that have a high weighting in terms of the number of individuals per hectare were identified. This information was based on the records of the transhumance routes in the region (PRONATURA-Veracruz, 2010), as well as information provided by $n=88$ beekeepers on the main blooms on each of the routes.

It was taken as a sample beekeepers population who issued record levels of infestation by Varroa destructor Anderson and Trueman (2000), as issued by the national governing body in the state delegation of SAGARPA. To estimate the sample size from a population of $\mathrm{N}=247$, a simple random sampling technique was used (Scheaffer et al., 1987), where:

$$
n=\frac{N \sigma^{2}}{(N-1) D+\sigma^{2}}
$$

$N=$ Number of hives

$n=$ Sample size

$\sigma=$ Standard deviation

$\mathrm{D}=$ Error disposition

Sample size $(\mathrm{n}=88)$ was obtained by replacing the following values in the formula: $\mathrm{N}=247$, the standard deviation of the number of hives $(\sigma)=200.6$ and $\mathrm{B}=34.4$, with $\alpha$ $=0.95$.

We used the Mexican productive crop potential method (Diaz et al., 2012) and geographic information system tools (scale 1:50,000), along with Series III climate (precipitation and temperature) data from the National Institute of Statistics and Geography (INEGI) and edaphoclimatic requirements of indicator species such as temperature, precipitation, elevation, soil type, depth and texture, and the salinity variable for the species that required it. Vector images were developed at the INIFAP Teocelo Experimental Site's Digital Agromap Laboratory; the images were reclassified at two levels: the high (1) and medium (2) development area based on the edaphoclimatic requirements of the species (Ruiz et al., 2011).

In parallel, the response in A. mellifera L. development to the environmental temperature was defined to predict the potential geographical distribution amplitude of the species, using the cartographic process employed for the productive potential of the melliferous plants.

In the final stage, an intersect of the resulting vector models between plants and bees was made to determine the spatial distribution for the beekeeping activity in the desired time period. The INIFAP National Environmental Information System (SIA for its acronym in Spanish) was used, with historical normal values for the period 1961-2003 (Ruiz et al., 2003), which was worked in raster format, adding algebraically the estimated future anomalies by Magaña and Caetano (2007) in their model SICC. The simulation of climate changes due to climate change in the short (2021-2030), medium (2041-2050) and long term (2051-2060) was based on the SICC assembly model proposed by Magaña and Caetano (2007) with weighted climate values from 10 General Circulation Models (mpi_echam5, miub_echo_g, csiro_mk3_0, csiro_mk3_5, cccma_cgcm3_1, giss_model_e_r, ncar_ccsm3_0, miroc3_2_hires, mri_cgcm2_3_2a, 
ukmo_hadcm3), with a resolution of $90 \mathrm{~m} \mathrm{x} 90 \mathrm{~m}$. This assembly presented changes according to scenario A2 contained in the AR4 published by the IPCC (2007).

With the SICC and SIA we calculated deviations of the study variables between the 1961-2003 climatology and the decades of short (2021-2030), medium (2041-2050) and long term (2051-2060) showing that the temperature will have an increase of 1.8 to 2 ${ }^{\circ} \mathrm{C}$, from tropical regions and high valleys such as the apicultural region of the study área.

The indicator melliferous species used for the present study were: Citrus sinensis (L.) Osbeck (lemon), Citrus paradisi Macf. (grapefruit), Bursera simaruba (L.) Sarg. (gumbo-limbo), Coffe arabica L. (coffee), Avicennia germinans L. (black mangrove), Rizophora mangle L. (red mangrove), Brassica nigra (L.) Koch (black mustard) and Spondias mombin L. (jobo) (Figure 1).

In the mapping process, waterbodies and urban areas were excluded because they included wild plants that did not correspond to specific crop areas. In addition, due to the similarity in edaphoclimatic requirements, the two citrus $(C$. sinensis and $C$. paradisi) and mangrove forest (A. germinans and $R$. mangle) species were grouped into two flowerings: citruses and mangrove. The changes in the area with productive potential for melliferous species were presented in units of hectares to quantify the changes in the spatial and temporal dimension based on the projection model.

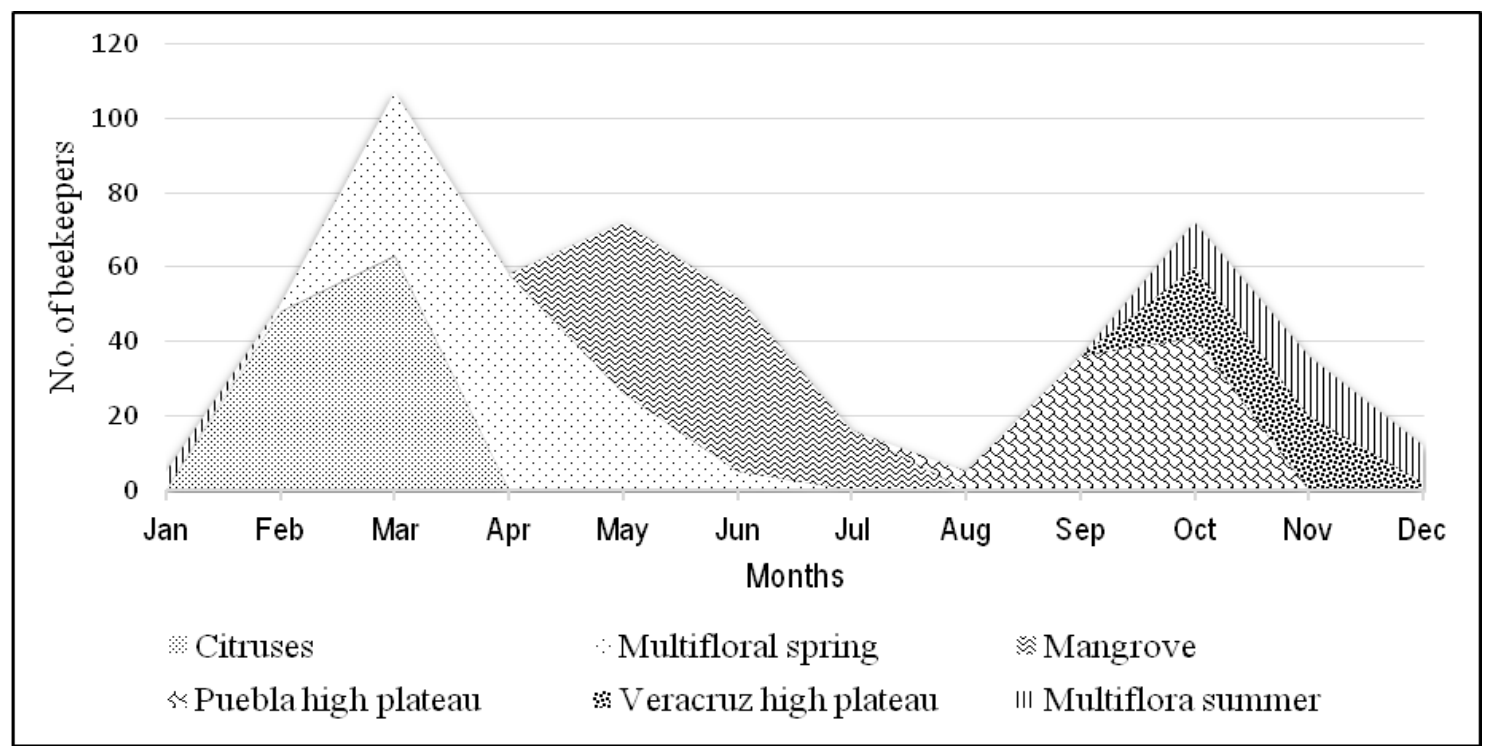

Figure 1. Temporality of blooms available in the beekeeping region of the Gulf of Mexico, based on the percentage of beekeepers

\section{Results and Discussion}

\section{Mobility of the melliferous flora}

Based on the projection model, it was found that the cultivated citrus species $(C$. sinensis and $C$. paradisi) showed a reduced area with high potential in the short $(57.6 \%)$, medium $(70.1 \%)$ and long term $(75.2 \%)$. The replacement of the area with high potential, by areas with characteristics of medium potential, reflected that the predictions of the simulation model for these species are negative. However, by being 
cultivated species, the impacts could be cushioned by human actions rather than by any response mechanisms they may have (Table 1).

Table 1. Percentage change in the melliferous flora area at temporal scale

\section{Level of change}

\begin{tabular}{|c|c|c|c|c|c|}
\hline Period & Indicator species & High & Trend & Medium & Trend \\
\hline Short term & Citruses & -57.6 & $\downarrow$ & 56.6 & $\uparrow$ \\
\hline \multirow[t]{5}{*}{$(2021-2030)$} & B. simaruba & 4.7 & $\uparrow$ & -8.2 & $\downarrow$ \\
\hline & C. arabica & 2.1 & $\uparrow$ & 8.3 & $\uparrow$ \\
\hline & Mangrove & 0.0 & $=$ & 0.0 & \\
\hline & B. nigra & -4.1 & $\downarrow$ & 0.9 & $\uparrow$ \\
\hline & S. mombin & 12.0 & $\uparrow$ & -12.4 & $\downarrow$ \\
\hline Medium term & Citruses & -70.6 & $\downarrow$ & 69.4 & $\uparrow$ \\
\hline \multirow[t]{5}{*}{$(2041-2050)$} & B. simaruba & 5.1 & $\uparrow$ & -7.9 & $\downarrow$ \\
\hline & C. arabica & & $\uparrow$ & -4.1 & $\downarrow$ \\
\hline & Mangrove & 0.0 & $=$ & 0.0 & \\
\hline & B. nigra & -3.3 & $\downarrow$ & 0.7 & $\uparrow$ \\
\hline & S. mombin & 13.6 & $\uparrow$ & -14.1 & $\downarrow$ \\
\hline Long term & Citruses & -75.2 & $\downarrow$ & 73.9 & $\uparrow$ \\
\hline \multirow[t]{5}{*}{ (2051-2060 } & B. simaruba & 5.0 & $\uparrow$ & -8.0 & $\downarrow$ \\
\hline & C. arabica & -1.9 & $\downarrow$ & -11.6 & $\downarrow$ \\
\hline & Mangrove & 0.0 & $=$ & 0.0 & \\
\hline & B. nigra & -3.0 & $\downarrow$ & 0.6 & $\uparrow$ \\
\hline & S. mombin & 4.0 & $\uparrow$ & -4.2 & $\downarrow$ \\
\hline
\end{tabular}

The sign (-) indicates reduction in area percentage value.

The citrus species involved in transhumant beekeeping are cash crops where production depends on characteristics such as technical handling, input and management, technological efficiency, soil, pests and diseases, productivity per tree and per hectare, management requirements, shipping costs and logistics (Neves et al., 2012). 
Thus, impacts caused by climatic variations that jeopardize production are only determined by the geographical and temporal location of these crops (Rosenzweig et al., 1996), so that climate change will exacerbate their spatial distribution problems (Fitchett et al., 2014).

For its part, $C$. arabica (coffee) is another cultivated indicator melliferous species that improves its production yields due to the presence of bees (Saturni et al., 2016). In this regard it was observed that in the short and medium term, the development area with high potential showed an increase of only 2.1 and $2.0 \%$, respectively, compared to the current potential area, but in the long term it had a reduction of $1.9 \%$ with respect to the current area values. Therefore, the variation between one period and another did not allow demarcating a positive or negative spatial trend (Table 1).

Although $C$. arabica showed a lower reduction percentage in the area with high productive potential, it coincides with reports from the Southern Sudan in Africa, where the loss of optimum area for coffee cultivation, under the A2A scenario, is up to $68 \%$. However, in contrast to the results of the model used in this study, the area of intermediate potential is reduced by $11.6 \%$, whereas in Africa this area increases by 95\% until the 2080s (Davis et al., 2012).

While the change in projected areas is greater in that reported by Davis et al. (2012), the reduction in the area with optimum conditions for coffee cultivation is confirmed in this study and the percentage difference between the two can be attributed to geographic factors and the structure and approach of the type of climatic modeling used (Zhang et al., 2015).

For the species $B$. nigra, the projection model showed a negative impact for the area with high development potential, with a $3 \%$ reduction in relation to the current area from the short to the long term (Table 1).

For their part, the mangrove species (A. germinans and $R$. mangle) showed no spatial changes in areas with high productive potential, so based on the A2 scenario these plant communities will not undergo changes (Table 1). However, the IPCC predicts that coastal systems will experience adverse impacts from inundation, flooding and coastal erosion, which can lead to a loss of area suitable for the development of these species (IPCC, 2014). Because they are bio-complex systems that involve changes in the relative increase in sea level, temperature and soil chemical conditions, mangrove ecosystems require a comprehensive approach to ecosystem management to understand their operation and the effects that climate change entails (Yañez-Arancibia et al., 2014, Day et al., 2008).

One hypothesis is that these ecosystems could benefit by undergoing a spatial and temporal expansion due to the effects of climate change, based on a possible tropicalization of the Gulf of Mexico (Yañez-Arancibia et al., 2014) excluding the impacts mentioned, as well as those generated by demographic, economic and urban growth that put the structure, composition, function and distribution of these ecosystems at risk (IPCC, 2014, Yañez-Arancibia et al., 2014).

The species that expanded their development areas were those that make up part of the wild vegetation, B. simaruba and S. mombin, as part of the spring and autumn flowering. In both species the climate projection model predicts a positive impact in the short, medium and long term, increasing the development area with high potential by $5 \%$ for $B$. simaruba and $4 \%$ for $S$. mombin, with respect to the current area.

The amplitude of intervals in the edaphoclimatic development characteristics of the species gave them greater tolerance to the changes that the model projects, which is why 
an increase in the development area in comparison with the cultivated species is predicted. However, according to the fifth IPCC report (2014), tree mortality and forest decline due to rising temperatures will increase in different regions, jeopardizing carbon storage, biodiversity, timber production, water quality and aesthetic value.

Therefore, whether there is an increase or reduction in the development area of the indicator species as a consequence of global warming will be subject to the dispersion ability of each species, based on its edaphoclimatic characteristics, tolerance intervals and associated fauna. As a result, spatial mobility will be different for each type of species or set of plant populations (Yañez-Arancibia et al., 2014).

\section{Thermal comfort of A. mellifera}

It was found that the space projected with optimum comfort conditions for bee $(A$. mellifera) development increased. Based on the thermal factor, the high potential development area showed an expansion in spatial distribution of $19 \%$ in the short term, $23.40 \%$ in the medium term and $25.4 \%$ in the long term, while the medium potential area decreased by $32.6 \%$ in the short term, $40.9 \%$ in the medium term and $45 \%$ in the long term, which indicates an increase in the geographical distribution, as a consequence of the variations in temperature that climate change entails in the A2 scenario.

These results confirm that temperature is one of the main determinants of the ecological role played by species (Hildrew et al., 2017) and biogeographical distribution (Jeffree and Jeffree, 1994, Bravo et al., 2011). Therefore, the amplitude of the geographical space for the bee (A. mellifera) predicts that it will favor the expansion in the current limits of areas with thermal comfort. As has been reported for other insects, bees will have a clear spatial mobility (Regniere, 2009; Kiritani, 2013). However, landscape modification and extensive agriculture are constant risk factors that promote the fragmentation of suitable habitats for beekeeping (Burkle et al., 2013) (Table 2).

Table 2. Percentage change in thermal comfort area for A. mellifera from short to long term

\begin{tabular}{lcccccc}
\hline Potential/period & Short & Trend & Medium & Trend & Long & Trend \\
\hline High & 19.0 & $\uparrow$ & 23.4 & $\uparrow$ & 25.4 & $\uparrow$ \\
Medium & -32.6 & $\downarrow$ & -40.9 & $\downarrow$ & -45.0 & $\downarrow$ \\
\hline
\end{tabular}

The sign (-) indicates reduction in area percentage value.

\section{Spatio-temporal mobility of beekeeping areas}

With the intersects, the area with optimum thermal comfort for bees and optimum development potential for melliferous plants in each type of flowering was projected.

In the citrus species ( $C$. sinesis and $C$. paradisi), negative changes were observed due to a 57.6\% loss of spatial distribution in the optimum area for beekeeping development from the short (2021-2030) to the long term (2051-2060), as well as in the species $S$. mombin, which showed a $12 \%$ reduction in distribution for the same period (Table 3) (Figure 2). 

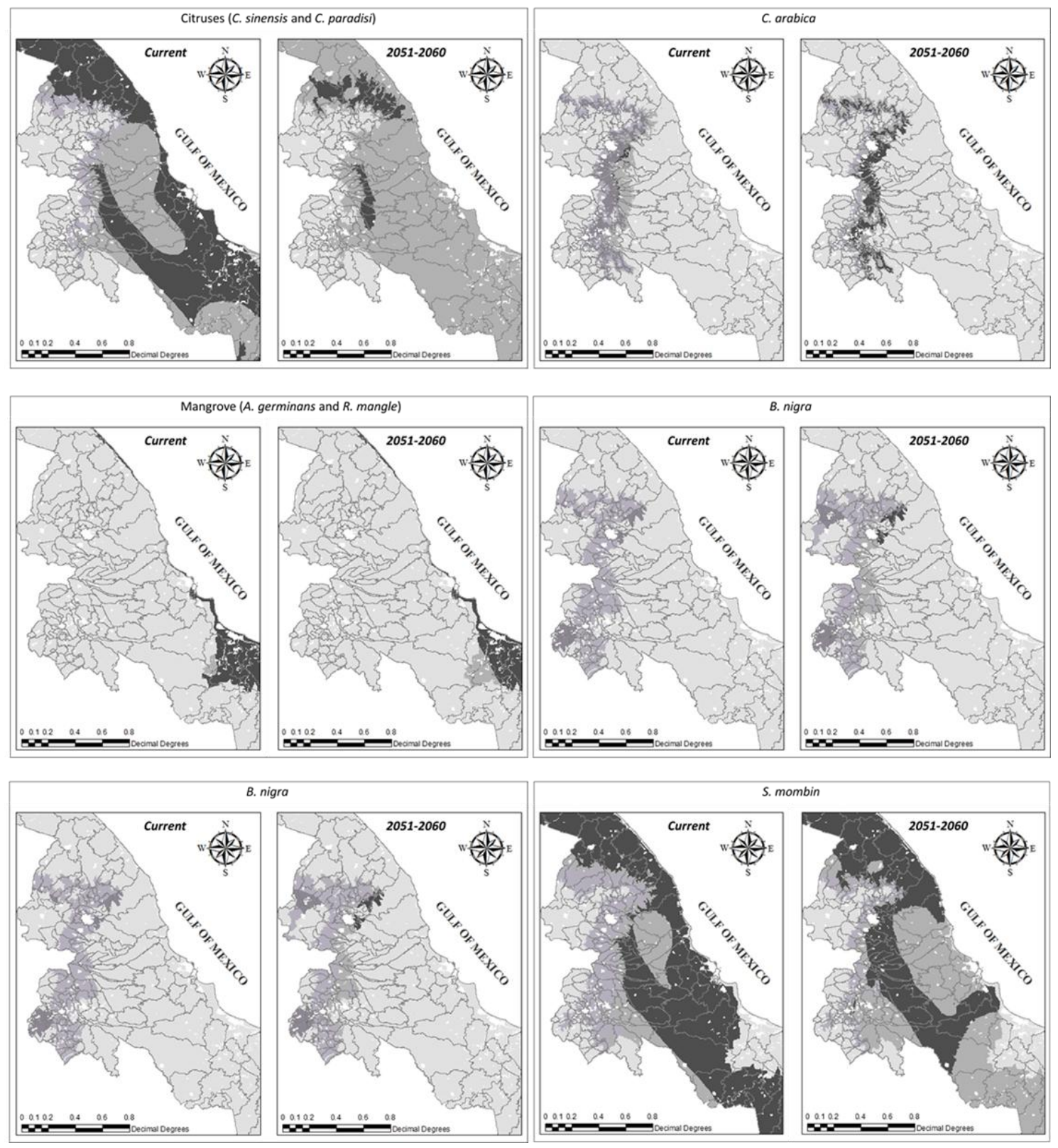

Figure 2. Predicted impact of climate change on beekeeping under current and future climatic conditions (scenario A2, IPCC)

Table 3. Percentage of the area of change in crosses made

\begin{tabular}{llrlcccccc}
\hline \multirow{2}{*}{ Period } & $\begin{array}{c}\text { Indicator } \\
\text { spp }\end{array}$ & $\begin{array}{c}\text { Plant(+) } \\
\text { Bee (+) }\end{array}$ & $\begin{array}{c}\text { Plant(+) } \\
\text { Bee (-) }\end{array}$ & $\begin{array}{c}\text { Plant(-) } \\
\text { Bee (+) }\end{array}$ & $\begin{array}{c}\text { Plant(-) } \\
\text { Bee (-) }\end{array}$ \\
\hline \multirow{6}{*}{ Short } \\
term & Citruses & -57.6 & $\downarrow$ & ------- & -- & 137.0 & $\uparrow$ & -81.0 & $\downarrow$ \\
& B. simaruba & 12.3 & $\uparrow$ & -100.0 & $\downarrow$ & 16.0 & $\uparrow$ & -57.6 & $\downarrow$ \\
& C. arabica & 683.2 & $\uparrow$ & -70.9 & $\downarrow$ & 37.6 & $\uparrow$ & -16.1 & $\downarrow$ \\
& Mangrove & 1.0 & $=$ & ------- & -- & ------ & -- & ------- & -- \\
& B. nigra & 9266.0 & $\uparrow$ & 41.4 & $\uparrow$ & 18514.0 & $\uparrow$ & -16.9 & $\downarrow$ \\
& S. mombin & -12.0 & $\downarrow$ & ------- & -- & 51.0 & $\uparrow$ & -52.0 & $\downarrow$ \\
\hline
\end{tabular}




\begin{tabular}{clrlcccccc}
\hline \multirow{4}{*}{$\begin{array}{c}\text { Medium } \\
\text { term }\end{array}$} & Citruses & -70.6 & $\downarrow$ & -------- & -- & 163.5 & $\uparrow$ & -91.9 & $\downarrow$ \\
& B. simaruba & 13.0 & $\uparrow$ & -99.6 & $\downarrow$ & 21.9 & $\uparrow$ & -68.1 & $\downarrow$ \\
& C. arabica & 835.3 & $\uparrow$ & -87.3 & $\downarrow$ & 29.3 & $\uparrow$ & -31.9 & $\downarrow$ \\
& Mangrove & 1.0 & $=$ & ------ & -- & ------- & -- & ------- & -- \\
& B. nigra & 9332.9 & $\uparrow$ & 42.5 & $\uparrow$ & 28946.0 & $\uparrow$ & -29.7 & $\downarrow$ \\
& S. mombin & 14.0 & $\uparrow$ & -------- & -- & 66.0 & $\uparrow$ & -65.0 & $\downarrow$ \\
\hline \multirow{5}{*}{ Long } & Citruses & -75.2 & $\downarrow$ & -------- & -- & -172.8 & $\downarrow$ & -95.7 & $\downarrow$ \\
& B. simaruba & 13.0 & $\uparrow$ & -99.4 & $\downarrow$ & -24.2 & $\downarrow$ & -72.6 & $\downarrow$ \\
& C. arabica & 850.2 & $\uparrow$ & -93.3 & $\downarrow$ & 24.3 & $\uparrow$ & -41.4 & $\downarrow$ \\
& Mangrove & -2.0 & $\downarrow$ & ------- & -- & ------- & -- & ------- & -- \\
& B. nigra & 9430.1 & $\uparrow$ & 42.5 & $\uparrow$ & 35056.0 & $\uparrow$ & -37.1 & $\downarrow$ \\
& S. mombin & 4.0 & $\uparrow$ & -------- & -- & 101.0 & $\uparrow$ & -70.0 & $\downarrow$ \\
\hline
\end{tabular}

By contrast, the projections for the species that are expected to broaden their spatial distribution due to an increase in the optimum development area for beekeeping from the short to the long term were the association of the bee with B. simaruba, B. nigra, and $C$. arabica, showing an expansion in area of the region suitable for bee development (Table 3) (Figure 2).

For their part, mangrove species (A. germinans and $R$. mangle) showed no changes in development area, maintaining the current area in the apicultural zones of the region in the three projected time periods. Therefore, the model does not foresee significant changes in beekeeping in these ecosystems due to the climatic variants (Figure 2).

Beekeeping is an activity that is established on the basis of available flowering, which is considered as one of the main elements in the industry (Khabbach et al., 2013, Al-Ghamdi et al., 2016). In this research it was observed that the distribution of apicultural zones with high potential for the insect and melliferous plants was not defined by any specific characteristic. However, the negative trend in citrus areas entailed by an average $1.9{ }^{\circ} \mathrm{C}$ temperature increase up to the long term (2051-2060) is a result of the effect of climate change.

This confirms what has been found in other studies (Delgado et al., 2012, Davis et al., 2012, Le Conte and Navajas, 2008, Redi et al., 2012, Lehébel-Péron et al., 2016) where it has been stated that increases in temperature, precipitation and relative humidity will affect the areas suitable for apicultural development, from phenological time-shifts to landscape modification, influencing the volume of production.

Because A. mellifera is generalist, it is believed that it may modify its foraging behavior in relation to the type of vegetation present (Gaines-Day and Gratton, 2016), since the intensity of visits is varied among the heterogenous blooms of the natural habitat, compared to crop blooms (Saturni et al., 2016).

The results of reclassifying the sites allowed confirming that there may be geographical expansion in areas with thermal comfort conditions for bees, congruent with the antecedents that foresee the territorial expansion of insect populations mainly due to the effect of temperature (Musolin and Saulich, 2012, Regniere, 2009, Le Conte and Navajas, 2008, Kiritani, 2013). Therefore, the thermal variations predicted in the A2 climatic scenario, of $1.9{ }^{\circ} \mathrm{C}$ up to the 2051-2060 decade in the area (Ruiz et al., 2011), could represent an advantage for the development of bees in the beekeeping 
region of the Gulf of Mexico and contribute to a greater number of areas that offer comfortable thermal development conditions for the bee.

It is thus expected that the transhumance routes, used by $91 \%$ of the beekeepers (Castellanos-Potenciano et al., 2015) in this apicultural region, will have a spatial and temporal mobility as a consequence of the changes in potential development areas, since climate fluctuations influence the availability of botanical resources (Medina-Cuéllar et al., 2014); however, the background of landscape modification, extensive agriculture and fragmented and deteriorated ecosystems where beekeeping is currently established (Burkle et al., 2013, Lehébel-Péron et al., 2016, Redi et al., 2012) continue to put this activity at risk.

\section{Conclusion}

In the short (2021-2030) medium (2041-2050) and long term (2051-2060), the indicator melliferous flora of the center of the state of Veracruz along the Gulf of Mexico will have a different spatio-temporal mobility, due to changes in temperature and precipitation as a result of climate change.

On the other hand, the current thermal comfort zone of $A$. mellifera $\mathrm{L}$. in the region will have an expanded territory and the spatio-temporal mobility will be positive in the short, medium and long term as a result of temperature change due to the effect of climate change, which will manifest itself in optimum honeybee development.

Based on the intersects, it was concluded that apiculture will have a varied spatiotemporal mobility in the short, medium and long term according to the availability of botanical resources and the thermal comfort of the bees, since according to the characteristics of each species, there will be a reduced territory for citrus species, linked to a negative impact on the high potential development area. On the other hand, the other six species will have an expanded territory that will result in a positive impact for the apicultural development of the region, as a function of the climatic characteristics.

Under the future scenario of beekeeping in this area, there will be an increase in the optimum area for honey production, due to the effect of climate change (temperature and precipitation) on spatio-temporal scales. It is therefore recommended that future research include new IPCC climate projection scenarios, the variation in floral phenology, the genetic adaptation potential of A. mellifera races and historical honey production volumes, as well as consider other climatic variables such as radiation and the chemical composition of the atmosphere.

Acknowledgements. We thank the Colegio de Postgraduados and the National Council of Science and Technology (CONACyT, for its acronym in Spanish) for doctoral program support.

\section{REFERENCES}

[1] Al-Ghamdi, A., Adgaba, N., Getachew, A. ,Tadesse, Y. (2016): New approach for determination of an optimum honeybee colonies carrying capacity based on productivity and nectar secretion potential of bee forages species. - Saudi Journal of Biological Sciences 23 (1): 92-100.

[2] Bravo, C. J., Sanchez, R. G. ,Gelviz, G. M. (2011): Estudio de la Distribucion de especies frente al Cambio Climatico. - Cuadernos de Biodiversidad. (ISSN 1575-5495) N35 (mayo 2011): 12-18. 
[3] Burkle, L. A., Marlin, J. C. ,Knight, T. M. (2013): Plant-Pollinator Interactions over 120 Years: Loss of Species, Co-Occurrence, and Function. - Science. 339 (6127):1611-1615. doi: 10.1126/science.1232728.

[4] Castellanos-Potenciano, B. P., Gallardo-López, F., Díaz-Padilla, G., Pérez-Vázquez, A., Landeros-Sánchez, C. ,Sol-Sánchez, Á. (2015): Apiculture in the humid tropics: Socioeconomic stratification and beekeeper production technology along the Gulf of Mexico. Agricultural Economics, Extension and Rural Development 3 (9): 321-329.

[5] CONAGUA. (2011): Reporte anual del clima en México. México: Servicio Metereológico Nacional, Gerencia de Meteorología y Climatología, Subgerencia de Pronóstico a mediano y largo plazo. http:// smn1.cna.gob.mx/ climatologia/analisis/ reporte/Anual2011.pdf

[6] Contreras-Escareño, F., Armendáriz, B. P., Echazarreta, C. M., Arroyo, J. C., MacíasMacías, J. O. ,Tapia-González, J. M. (2013): Present situation and characterististics of beekeepers in the South and Southeastern regions of the State of Jalisco, Mexico. [Características y situación actual de la apicultura en las regiones Sur y Sureste de Jalisco, Mexico], Revista Mexicana de Ciencias Pecuarias ISSN: 2007-1124, 4 (3): 387-398. http://www.redalyc.org/pdf/2656/265628467005.pdf

[7] Davis, A. P., Gole, T. W., Baena, S. ,Moat, J. (2012): The Impact of Climate Change on Indigenous Arabica Coffee (Coffea arabica): Predicting Future Trends and Identifying Priorities. - PLoS ONE 7 (11): e47981.

[8] Day, J. W., Christian, R., Boesch, R., Yáñez-Arancibia, A., Morris, J., Twilley, R., Naylor, L., Schaffner, L. ,Stevenson, C. (2008): Consequences of climate change on the ecogeomorphology of coastal wetlands. - Estuaries and Coasts. 37: 477-491.

[9] Delgado, D. I., Eglee, P. M., Galindo-Cardona, A., Giray, T. ,C., R. (2012): Forecasting the Influence of Climate Change on Agroecosystem Services: Potential Impacts on Honey Yields in a Small-Island Developing State. - Psyche, A Journal of Entomology Volume 2012, Article ID 951215, 10 pages, http://dx.doi.org/10.1155/2012/951215

[10] Diaz, P. G., Guajardo, P. R. A., Medina, G. G., Sánchez, C. I., Soria, R. J., Vásquez, A. J. M., Quijano, C. J. A., Legorreta, P. F. ,Ruiz, C. J. A. 2012. Potencial productivo de especies agrícolas de importancia socioeconómica en México. In: SAGARPA (ed.). Xalapa Ver.: INIFAP. Instituto Nacional de Investigaciones Forestales, Agrícolas y Pecuarias, ISBN 978-607-425-766-3, http:// www.cmdrs.gob.mx/ sesiones/ Documents/2012/5_sesion/inifap_estudio.pdf, Progreso No. 5, Barrio de Santa Catarina

[11] Fitchett, J. M., Grab, S. W., Thompson, D. I. ,Roshan, G. (2014): Spatio-temporal variation in phenological response of citrus to climate change in Iran: 1960-2010. Agricultural and Forest Meteorology 198-199: 285-293.

[12] Gaines-Day, H. R., Gratton, C. (2016): Crop yield is correlated with honey bee hive density but not in high-woodland landscapes. - Agriculture, Ecosystems \& Environment 218 53-57.

[13] Gomez-Diaz, D., Monterroso-Rivas, A., Tinoco-Rueda, J. ,López-García, J. (2007): Comportamiento de la vegetación bajo escenarios de cambio climático en la reserva de la Biosfera, Barranca de Metztitlán, Hidalgo, México. - Zonas Aridas 11 (1): 61-69.

[14] Guemes, R., Francisco, Echazarreta, G., Carlos, Villanueva, G., Rogel, Pat, F., Juan, Gomez, A., R. (2003): La apicultura en la península de Yucatán. Actividad de subsistencia en un entorno globalizado. - Revista Mexicana del Caribe 8 (16): 117-132.

[15] Hegland, S. J., Nielsen, A., Lázaro, A., Bjerknes, A.-L. ,Totland, Ø. (2009): How does climate warming affect plant-pollinator interactions? - Ecology Letters 12 (2): 184-195.

[16] Hildrew, A. G., Durance, I. ,Statzner, B. (2017): Persistence in the longitudinal distribution of lotic insects in a changing climate: a tale of two rivers. - Science of The Total Environment 1 (574): 1294-1304.

[17] Huerta, G. (2008): La Apicultura en el desarrollo. - Presencia. Bariloche, Argentina: INTA EEA 52: 25-27 
[18] IPCC. (2014): Cambio climático 2014 Impactos adaptación y vulnerabilidad. In: OMM, PNUMA (eds.) Contribución de grupo de trabajo II al Quinto Informe de Evaluación del Grupo Intergubernamental de Expertos sobre el Cambio Climático

[19] Jeffree, E. P. ,Jeffree, C. E. (1994): Temperature and the Biogeographical Distributions of Species. - Functional Ecology 8 (5): 640-650.

[20] Khabbach, A., Libiad, M. ,Ennabili, A. (2013): Melliferous flora and apiculture in the pre-rif of the province of taza (North of Morocco). - Luna Azul 36: 78-90.

[21] Kiritani, K. (2013): Different effects of climate change on the population dynamics of insects. - Applied Entomology and Zoology 48 (2): 97-104.

[22] Le Conte, Y. ,Navajas, M. (2008): Climate change: impact on honey bee populations and diseases. - Rev. sci. tech. Off. int. Epiz. 27 (2): 499-510.

[23] Lehébel-Péron, A., Sidawy, P., Dounias, E. ,Schatz, B. (2016): Attuning local and scientific knowledge in the context of global change: The case of heather honey production in southern France. - Journal of Rural Studies 44: 132-142.

[24] Magaña, M., Miguel, Tavera, C., Maria, Salazar, B., Lucila ,Sanginés, G., Jose (2016): Productividad de la apicultura en México y su impacto sobre la rentabilidad. - Revista Mexicana de Ciencias Agricolas 7 (5):1103-1115

[25] Magaña, V. ,Caetano, E. (2007): Informe final. CliMÁTiCO, D. G. D. I. S. C. Pronóstico climático estacional regionalizado para la República Mexicana como elemento para la reducción de riesgo, para la identificación de opciones de adaptación al cambio climático y para la alimentación del sistema: cambio climático por estado y por sector. México: Universidad Nacional Autónoma de México, SEMARNAT, Instituto Nacional de Ecología, Centro de Ciencias de la Atmosfera UNAM.

[26] Medina-Cuéllar, S. E., Portillo-Vázquez, M., García Álvarez-Coque, J. M., TerrazasGonzález, G. H. ,Alba-Nevárez, L. L. (2014): Influencia del ambiente sobre la productividad de la segunda cosecha de miel de abeja en Aguascalientes de 1998 a 2010. Revista Chapingo. - Serie ciencias forestales y del ambiente 20 159-165.

[27] Mendizabal, F. (2005): Abejas, Buenos Aires, Republica de Argentina. 255 pp

[28] Musolin, D. L. ,Saulich, A. K. (2012): Responses of insects to the current climate changes: from physiology and behavior to range shifts. - Entomological Review 92 (7): 715-740.

[29] Neves, F., Trombin, M., Lopes, F., Kalaki, R. ,Milan, P. (2012): Impact of climate change on citrus growing. - Wageningen Academic Publishers, doi: 10.3920/978-90-8686-7394_18

[30] PRONATURA-Veracruz, A. (2010): La Miel del Centro de Veracruz y sus Ecosistemas. Coatepec, Ver.: Zentmyer, Eric Ramirez-Soto, Anibal Porter- Bolland, Luciana.

[31] Redi, R., Verghese, A. ,Rajan, V. (2012): Potential impact of climate change on honeybees (Apis spp.) and their pollination services. - Pest Management in Horticultural Ecosystems 18 (2): 121-127.

[32] Regniere, J. (2009): Prediccion de la Distribucion continental de Insectos a partir de la fisiologia de las especies. - Unasylva 60 (231/232): 37-42.

[33] Rosenzweig, C., Phillips, J., Goldberg, R., Carroll, J. ,Hodges, T. (1996): Potential impacts of climate change on citrus and potato production in the US. - Agricultural Systems 52 (4): 455-479.

[34] Ruiz, C. J., Flores, L. H., Manriquez, O. J. (2011): Indices Bioclimáticos y Confort Ambiental para Ganado en Jalisco, México, Morelos, Jalisco. - Centro de Investigacion Regional "Pacifico Centro".

[35] Ruiz, C. J. A., González, A. I. J., Regalado, R. J. R., Anguiano, C. J., Vizcaíno, V. I., González, E. D. R. (eds.) (2003): Recursos edafo-climáticos para la planeación del sector productivo en el Estado de Jalisco. - INIFAP-CIRPAC.

[36] Saturni, F. T., Jaffé, R. ,Metzger, J. P. (2016): Landscape structure influences bee community and coffee pollination at different spatial scales. - Agriculture, Ecosystems and Environment 235: 1-12. 
[37] Scheaffer, R., William, M., Lyman, O. (1987): Elementos del Muestreo. - Grupo Editorial Iberoamericana.

[38] SIAP. (2015): Resumen estatal pecuario. Producción, Precio y Valor de la miel 2013 ed. México: SAGARPA.

[39] Tam, J., McDaniels, T. L. (2013): Understanding individual risk perceptions and preferences for climate change adaptations in biological conservation. - Environmental Science \& Policy 27 114-123.

[40] Villegas, D. G., Bolaños, M. A., Sandoval, H. R. ,Lizama, M. J. 2003. Flora Nectarifera y Polinifera en el estado de Veracruz. - SAGARPA (ed.) 2 ed. México.

[41] Yañez-Arancibia, A., Day, J., Twilley, R. ,Day, R. (2014): Mangrove swamps: sentinel ecosystem in front of the climatic change, Gulf of Mexico. - Madera y Bosque 20 (Especial): 39-75.

[42] Zhang, Y., Zhao, Y., Chen, S., Guo, J. ,Wang, E. (2015): Prediction of Maize Yield Response to Climate Change with Climate and Crop Model Uncertainties. - Journal of Applied Meteorology and Climatology 54 (4): 785-794.

[43] Zhou, J., Cai, W., Qin, Y., Lai, L., Guan, T., Zhang, X., Jiang, L., Du, H., Yang, D., Cong, Z. ,Zheng, Y. (2016): Alpine vegetation phenology dynamic over 16 years and its covariation with climate in a semi-arid region of China. - Science of The Total Environment 572 119-128. 